E. G. Christensen, Y. Hu, D. M. J. Purnomo, G. Rein, Influence of Wind and Slope on

Multidimensional Smouldering Peat Fires, Proceedings of the Combustion Institute (2020)

available at: https://doi.org/10.1016/j.proci.2020.06.128

\title{
Influence of Wind and Slope on Multidimensional Smouldering Peat Fires
}

\author{
Eirik G. Christensen ${ }^{1}$, Yuqi Hu ${ }^{1}$, Dwi M. J. Purnomo ${ }^{1}$, Guillermo Rein ${ }^{1 *}$ \\ ${ }^{1}$ Department of Mechanical Engineering and Leverhulme Centre for Wildfires, Environment and \\ Society, Imperial College London, London, SW7 2AZ \\ *Corresponding author
}

\begin{abstract}
Smouldering peat fires are the largest fires on Earth, destroying an important ecosystem, and releasing large quantities of smoke, which is responsible for health issues and carbon emissions. Here we study the influence of wind direction (forward, perpendicular, opposed) and slope (uphill, side hill, downhill) on multidimensional smouldering spread, using a shallow open reactor. These conditions are known to be controlling variables in spread dynamics of flaming wildfires; however, wind and slope are rarely studied for smouldering wildfires. We conducted 21 experiments and compare the data to an additional 15 experiments from the literature. Where airflow was concurrent with spread (forward wind and uphill), both wind and slope increased the horizontal and in-depth spread rates by up to $101 \%$ and $32 \%$, respectively, from quiescent and flat conditions. When airflow was perpendicular to spread (perpendicular wind and side hill), horizontal spread rate was increased by wind (up to 21\%), but was negligibly influenced by slope. Airflow opposite to the spread direction (opposed wind and downhill) resulted in a negligible change in horizontal spread with wind, but a decrease in horizontal spread of up to $40 \%$ due to slope. We also found that spread in any direction on a slope can be evaluated as a function of the angle of the spread relative to the horizontal plane, regardless of the slope of the terrain. Our findings provide new insight into important field conditions affecting smouldering wildfires and provide a better understanding of their spread.
\end{abstract}

\section{Introduction}

Smouldering is the slow, low temperature, flameless form of combustion, which propagates through porous fuels [1]. Smouldering contributes significantly to the total amount of biomass consumption in wildfires [2], burning deep into organic soil for periods lasting up to several weeks, while flaming fires quickly consume surface vegetation and the top soil [1]. Smouldering wildfires are most notable in peatlands, a soil composed of partially decomposed material which accumulates over centuries to millennia in regions where the moisture is too high, or the temperatures are too low for significant decomposition [3]. Smouldering of these old layers of organic-rich soil provides a rapid means of releasing the carbon into the atmosphere [4].

In organic soils, such as peat, smouldering spreads both horizontally and in-depth. Horizontal spread is on the same plane as the surface of the soil, whereas in-depth spread is into the bulk of the material. These burning dynamics are influenced by the physical parameters of the soil. The most important of them is moisture content (MC), which is the measure of the amount of water in a soil [5]. MC decrease horizontal spread rates due to the increased energy required to dry the soil [6], and increase in-depth spread rate because of peat swelling, resulting in greater oxygen supply and burning rate [7].

Little is known about the influence of environmental conditions such as wind and slope of the ground on the smouldering of peat This is despite these factors being prevalent in nature, present to varying degrees in all wildfires, and are heavily studied parameters in flaming wildfires $[9,10]$. In particular, no studies have examined the effect of wind or slope on in-depth spread; the parameter which governs 
the emissions per unit area for smouldering wildfires [7]. The little research to date focused on smouldering spread exposed to wind or slopes has found that horizontal spread is increased by wind when in the same direction as spread, as found in studies on pine needles [11] and dust layers [12], because the unburned material is heated convectively, assisting the drying and preheating process. This mechanism also increases the maximum fuel moisture content through which smouldering can be sustained [11]. This concurrent orientation of airflow and spread direction is known as forward spread [13]. Opposed spread is when airflow and spread are in opposite directions [14]. Palmer [12] found that opposed flow, over piles of dust, increased horizontal spread to a small degree but was insensitive to wind speeds. . Wind has also been demonstrated to enable the transition from smouldering to flaming [15], which can frustrate fire-fighting efforts and presents an increase in spread rate and hazard.

For comparison, flame spread rates increase non-linearly with increasing uphill gradients or concurrent winds, and decrease slightly downhill or in opposing wind $[9,10]$. This behaviour is explained by the heat transfer from the flame to the fuel. Both slope and wind cause the flame to tilt towards the fuel, increasing radiative and convective heat transfer and dramatically increasing spread rates $[9,16]$. Thus the dynamics found for flaming fires cannot be applied to smouldering fires.

In this paper we, for the first time, study the effect of slope and wind direction on both horizontal and in-depth spread rate of smouldering peat to gain a fundamental understanding of these two prevalent factors in smouldering wildfires that have received little attention to date.

\section{Method}

Two sets of experiments were conducted to, separately, study wind and slope using a shallow opentop reactor constructed from insulating board with internal dimensions of $40 \times 40 \times 1.6 \mathrm{~cm}$ as illustrated in Figure 1.21 experiments were conducted with wind and slopes as the main variables and the results were compared to experiments in literature [17] performed with the same setup, but without wind or slope. The experimental set-up makes it feasible to conduct a much larger number of experiments, due to the reduced experimental time required, and gain insights that are not possible with deeper reactors.

Commercial milled Irish Sphagnum peat (Shamrock Irish Moss Peat, Bord na Mona Horticulture) was selected for use, due to its homogeneous properties and frequent use in literature $[8,17]$. The fuel was selected such that it would produce repeatable results by limiting fuel heterogeneity and allowing for influencing factors to be isolated. The peat had a composition of 54.1/5.1/1.3/0.5\% mass fraction of $\mathrm{C} / \mathrm{H} / \mathrm{N} / \mathrm{S}$ respectively, and an inherent inorganic content $\left(\mathrm{IC}_{0}\right)$ of $2.5 \pm 0.6 \%$ [17].

To prepare the samples, the soil was placed in an oven at $80^{\circ} \mathrm{C}$ until dry and sieved to remove particles larger than $8.5 \mathrm{~mm}$ to improve consistency and ease of levelling the peat to the reactor. Water was then added to achieve a desired MC, which is calculated by dividing the mass of water by the mass of dry peat. For wind, MC of 0, 40, 80, and $120 \%$ were studied. This covers the span of MC that can selfsustain smouldering [17]. For experiments on slope, an $80 \% \mathrm{MC}$ was targeted. To verify the MC, a $100 \mathrm{~g}$ subsample from of the conditioned peat was dried at $90^{\circ} \mathrm{C}$ for $7 \mathrm{~h}$ [17]. All samples were within $5 \%$ of their targeted MC. Each MC condition was repeated 3 times, to capture natural variability and reduce uncertainty. The reactor was filled with the conditioned soil and the mass of each sample was recorded. The bulk density $\left(\rho_{b}\right)$ and organic density $\left(\rho_{o}\right)$ (which is the density of combustible material in the soil; calculated using Eq. 1) were then calculated.

$$
\rho_{o}=\frac{m(1-I C)}{V(M C+1)}
$$


Where $\mathrm{m}$ is the mass of the sample and $\mathrm{V}$ is the volume of the reactor $\left(0.00256 \mathrm{~m}^{3}\right)$. The densities and $\mathrm{MC}$ of the 3 replicates for each condition were averaged and are presented in table S1 for posterity. The average standard deviation in densities of the replicates was $5 \%$.

The samples were ignited at the centre by supplying $20 \mathrm{~W}$, for $30 \mathrm{~min}$, to a $0.5 \mathrm{~mm}$ nichrome wire wrapped in a $10 \mathrm{~mm}$ long helical coil with a diameter of $10 \mathrm{~mm}$ [17]. Igniting at the centre of the sample allowed for the study of spread in all directions relative to both wind and slope.

Wind was applied along the surface of the peat, using two, $30 \mathrm{~cm}$ wide, tangential fans placed on top of each other. The fans were placed $20 \mathrm{~cm}$ from the edge of the reactor to allow the boundary layer to develop. Characterization of the flow was performed by measuring wind speeds at between 10 and 60 $\mathrm{cm}$ from the fan, 0 to $15 \mathrm{~cm}$ from the centreline of the fan, and at several heights using a hotwire anemometer (Figure S1). The measurement of smouldering dynamics were limited to within $14 \mathrm{~cm}$ of the ignition where wind speed was found to be consistent. The wind speed measured within the region considered for study (30-50 cm from fan; 0 and $7.5 \mathrm{~cm}$ from the centreline, $1 \mathrm{~cm}$ above the surface, illustrated in figure S2) averaged $0.86 \pm 0.12 \mathrm{~m} / \mathrm{s}$. This is a similar order of magnitude to smouldering experiments in literature $[8,11,15]$.

Higher wind velocities resulted in smouldering particles of peat being carried forward altering the spread mechanism. Only the maximum wind speed was selected as it would have the greatest effect on the smouldering dynamics.

For the study of slope, the reactor was inclined using a lab jack, and the slope was measured using a protractor (Figure 1). Three slopes $(\alpha), 10^{\circ}, 20^{\circ}$, and $30^{\circ}$ relative to horizontal were studied and compared to spread in a horizontal configuration $\left(\alpha=0^{\circ}\right)$. Each inclination was performed 3 times, to capture natural variation of the peat bed and uncertainties.

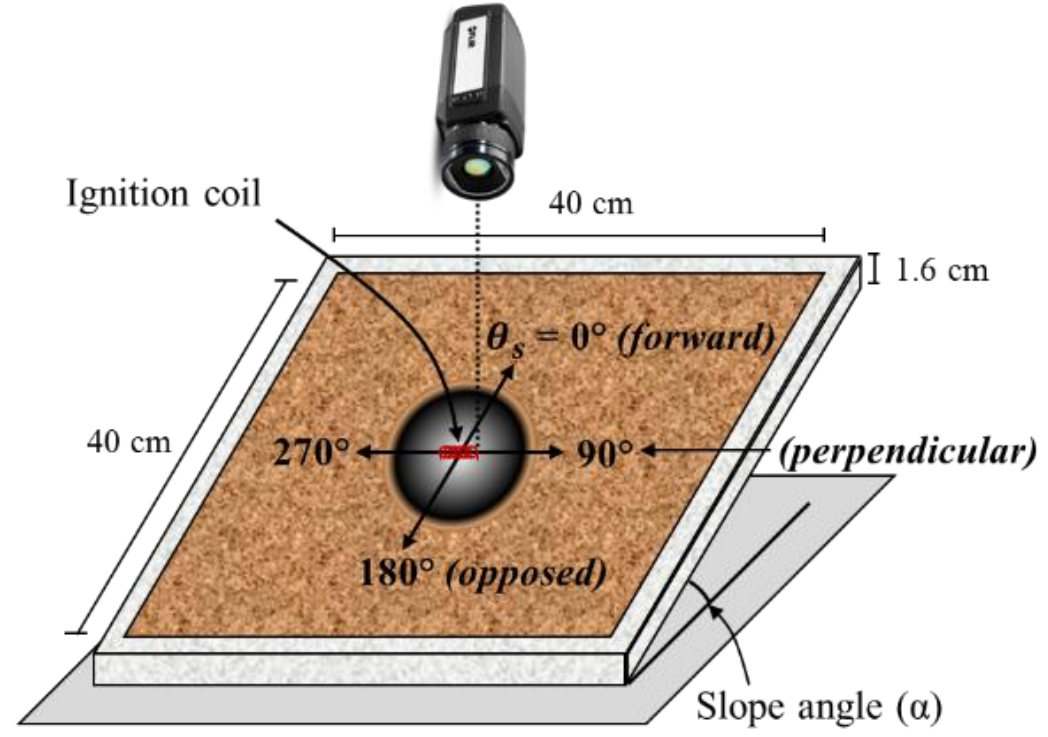

Figure 1 - Illustration of experimental set up for studying the influence of slope on smouldering dynamics. When $\theta_{s}$ is equal to 0 and $180^{\circ}$, smouldering spreads uphill or downhill, respectively.

Smouldering spread rates were analysed in an identical manner as presented in previous work [17]. To explain briefly, an infrared (IR) camera (FLIR A655sc) was placed directly above the centre of the reactor with an imaging frequency of $1 \mathrm{~min}$ (Figure 1). The images were then converted into grayscale, and in the case of the slope experiments the images were corrected for the effect of perspective. Sixty transects capturing the pixel intensity profile were used to measure spread. Where the pixel profile first and last exceeded a normalized threshold of 0.2 was identified as the trailing and leading edge of 
smouldering, respectively. The results were insensitive to the specific threshold value due to the steep slope of the pixel profile. Comparing the location of these edges in images separated by 10 min apart allows for the calculation of spread rate. The leading edge directly relates to the horizontal spread rate, while in-depth spread rate was calculated using Eq. 2; where $\mathrm{H}$ is the thickness of the sample bed (1.6 $\mathrm{cm}$ ), and $\mathrm{t}_{\mathrm{b}}$ is the burning time which is the time taken between the leading and trailing edge reaching any one point. Figure 2 illustrates this analysis framework, and shows how the features manifest in the IR images. Here horizontal spread rate refers to spread in the same direction as the surface of the peat, while in-depth spread is perpendicular to the surface (into the bulk of the material). In both wind and slope experiments the horizontal and in-depth spread rate reached a steady state and so the average spread rates are reported (Fig. S3). Small fluctuations of spread rate during the steady state spread were observed, and is likely due to natural variation in soil properties or airflow.

$$
S_{d}=\frac{H}{t_{b}}
$$
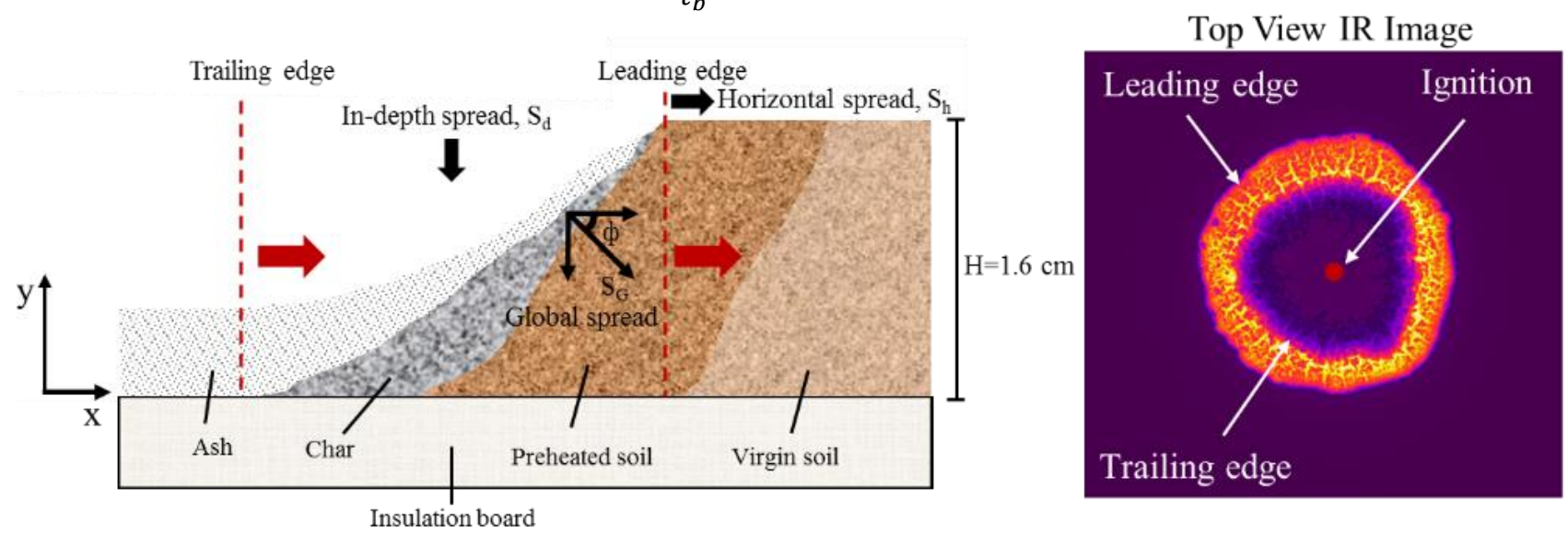

Figure 2 -A cross section illustrating the key features of smouldering dynamics (left), and a top view IR image showing how the features manifest (right). Figure is modified from [17].

\section{Results and discussion}

\subsection{Effect of wind}

Figure 3 illustrates the influence of wind direction, relative to smouldering spread $\left(\theta_{\mathrm{w}}\right)$, and MC on horizontal spread rate $\left(S_{\mathrm{h}}\right)$. We focus on three directions: forward $\left(\theta_{\mathrm{w}}=0^{\circ}\right)$, perpendicular $\left(\theta_{\mathrm{w}}=90^{\circ}\right.$, $270^{\circ}$ ), and opposed $\left(\theta_{\mathrm{w}}=180^{\circ}\right)$. Polar plots of all relevant spread dynamics are provided in Figure S4. 


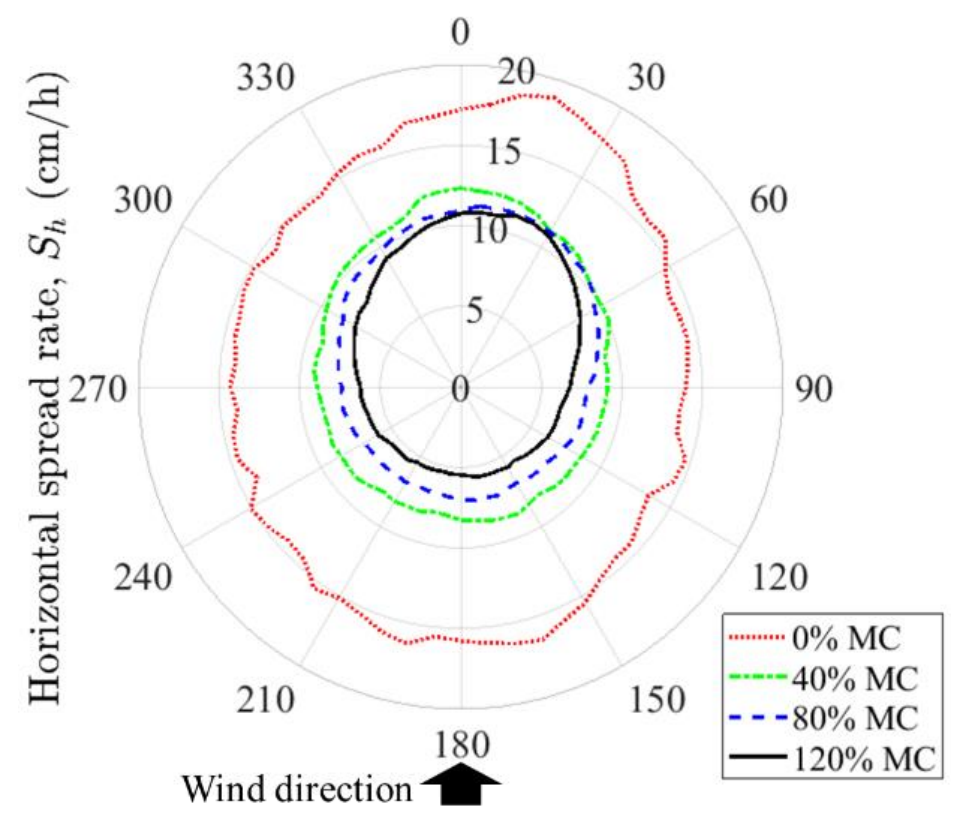

Figure 3 -Polar plot of the influence of wind direction and MC on horizontal spread rate. Radial axis is spread rate $(\mathrm{cm} / \mathrm{h})$ while the angular axis is the direction $\theta_{w}$. Where $\theta_{w}=0,90$, and $180^{\circ}$ is forward perpendicular and opposed respectively.

As reported by [17], MC decreases horizontal spread and increases in-depth spread. However, both horizontal and in-depth spread rates in forward spread mode were greatly increased by wind, relative to no-wind conditions (Figure $4 \mathrm{a}$ and b). At $120 \% \mathrm{MC}$, horizontal and in-depth spread rate was $100 \%$ and $37 \%$ faster than in quiescent conditions respectively, while in dry peat the increase was only $44 \%$ and $22 \%$ respectively. This shows that both horizontal and in-depth spread rate are increasingly sensitive to wind with increasing MC, and that horizontal spread is affected more by wind than indepth spread. This is in contrast to findings presented by Huang et al. [8] and Valdivieso and Rivera [11]. Huang et al. [8] found a $\sim 140 \%$ increase in horizontal spread between wind speeds of 0 and 1.2 $\mathrm{m} / \mathrm{s}$ in $5 \%$ MC peat, but only a $\sim 30 \%$ increase in samples of $100 \% \mathrm{MC}$, suggesting that horizontal spread rate was less sensitive to wind with greater MC. The difference in results may be due to a greater sample depth $(10 \mathrm{~cm})$ and an increase in burning depth with $\mathrm{MC}$, which protects the smouldering from the wind.

Where the wind was perpendicular, horizontal and in-depth spread rate increased slightly, while no change in spread was observed where wind was in the opposite direction (Figure $4 \mathrm{a}$ and b). This is in agreement with [12], which observed a minor increase in horizontal spread rate with opposed wind and insensitivity to wind speed in studies on dust (grass, cork, and beech sawdust). Ohlemiller [18], however, found a small linear increase with opposed wind speed in samples of cellulosic insulation. For comparison, flaming fires, also see a decrease in opposed spread rates due to convective cooling and reduced radiative heating as the flame is tilted away from the fuel, and see a strong positive influence in forward wind conditions [16].

For horizontal spread rate, the difference between forward and opposed wind is $9 \%$ at $0 \% \mathrm{MC}$ and increases to $98 \%$ at $120 \%$ MC. While in-depth spread rates changed from a $2 \%$ difference at $0 \% \mathrm{MC}$ to $30 \%$ at $120 \% \mathrm{MC}$. The difference between forward and opposed horizontal spread can be attributed to preheating by smoke flowing over the peat ahead of the pyrolysis front, as observed by Valdivieso and Rivera [11] with smouldering pine needles. In contrast, for opposed flow, airflow convection cools the smouldering front.

The burning rate $(\dot{m})$, which measures how quickly fuel is consumed, was calculated using Eq. 3 , and was found to increase with MC (Figure $4 \mathrm{c}$ ). This is in consistent with [7] who conducted in-depth 
smouldering spread experiments in a 30cm column of peat, and [17] which is used as the comparison for no-wind conditions. The burning rate was observed to be greater in the forward condition compared to opposed. Both forward and perpendicular wind directions increased the burning rate compared to no-wind conditions, while the opposed flow did not result in any increase in burning rate. The increase in burning rate in the forward spread condition suggests an improved air supply leading to a greater rate of char oxidation.

$$
\dot{m} "=S_{d} \rho_{o}
$$

For the condition with higher burning rates, we also observed an increased radiative heat flux measured by the IR camera. It was found that forward spread radiated more heat than opposed spread by up to 53\%. The heat flux from the forward spread was greater than in quiescent conditions but insensitive to $\mathrm{MC}$, while heat flux decreased with $\mathrm{MC}$ in opposed spread and was similar to that than in quiescent conditions (Figure S5). The difference in heat flux could also be visually observed as forward spread often glowed, suggesting a higher local temperature which also contributes to increasing the horizontal spread rate.

a)

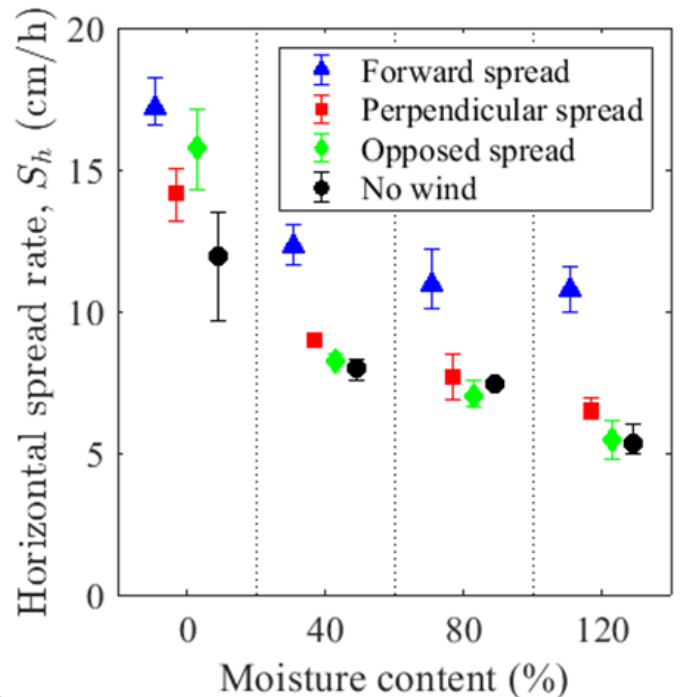

c)

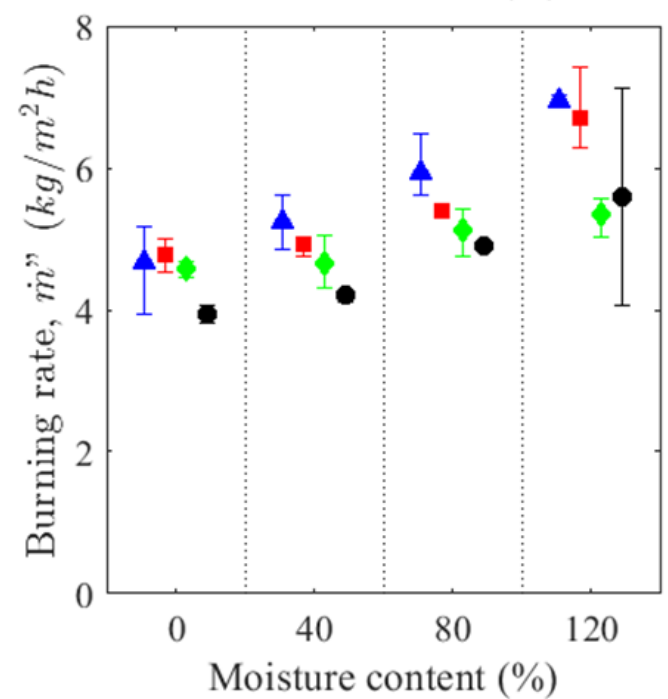

b)

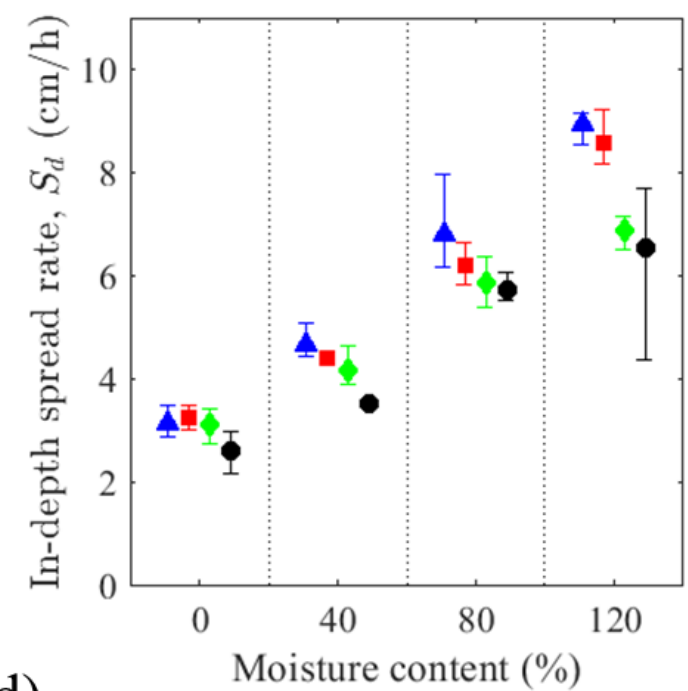

d)

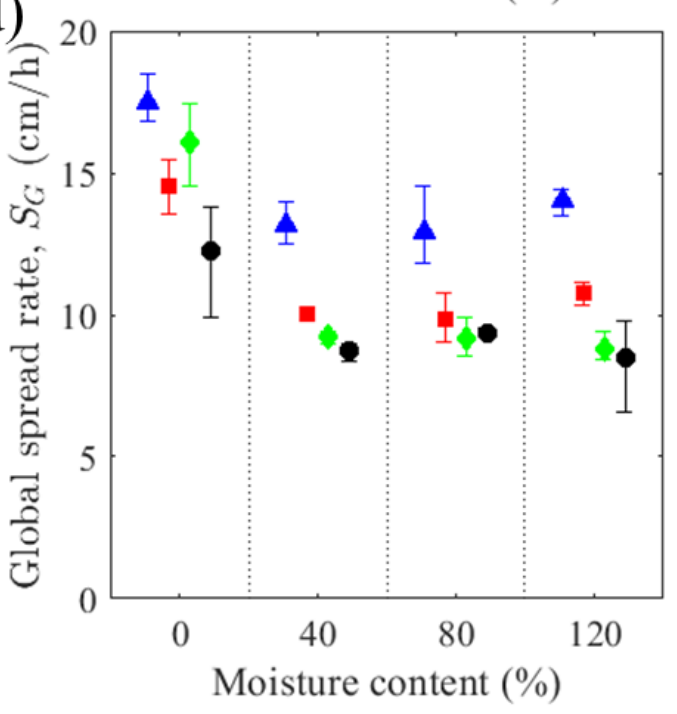

Figure 4 - Influence of MC and wind direction on a) horizontal spread rate, b) in-depth spread rate, c) burning rate, and d) global spread rate. The results are offset from MC values and each moisture condition is separated by dotted lines. The error bars show the range of experimental results from three repetitions. The results for no wind conditions were taken from [17].

Combining the horizontal and in-depth spread rates as vector components gives the global spread rate $\left(\mathrm{S}_{\mathrm{G}}\right)$ with a direction $\phi$ (Figure 2). This concept was first discussed in [17]. Figure $4 \mathrm{~d}$ shows that the 
global spread rate was influenced by wind direction with the forward and perpendicular spread increasing compared to no wind conditions, while opposed spread was negligibly affected by wind. The global spread appears to be independent of MC, apart from the unusual behaviour of dry peat. This independence of global spread rate with MC was also reported in [17], but is shown here to also be true for all wind conditions. The direction of spread was also found to be more horizontal in the forward mode (a smaller angle of $\phi$ ) than in quiescent conditions and went more in-depth with increasing MC (Figure S6). An overview of the smouldering dynamics as a function of wind direction is provided in Table $\mathrm{S} 2$.

\subsection{Effect of slope}

A polar plot showing the horizontal spread rate in all directions as a function of slope is shown in Figure 5. Compared to spread on a flat fuel bed $\left(\alpha=0^{\circ}\right)$, horizontal spread increased uphill $\left(\theta_{\mathrm{s}}=0^{\circ}\right)$ by $21 \%$ for $\alpha=20^{\circ}$, decreased by $8 \%$ downhill $\left(\theta_{\mathrm{s}}=180^{\circ}\right)$ and was insensitive to slope (Figure 5 and Figure 6a). It can also be noted that uphill spread increases with slope. These findings are consistent with experiments performed by Palmer [12] with insulation fibre boards. Palmer [12], found an average increase of $26 \%$ in horizontal spread between $0^{\circ}$ and $30^{\circ}$ inclination, and an average increase of only $8 \%$ for spread down a $-30^{\circ}$ slope. Polar plots of all other relevant spread dynamics are provided in Fig. S7. Notably, on slopes of $30^{\circ}$, char uphill was observed to slip resulting in unreliable measurements and so spread dynamics affected by this behaviour are removed from the results. The slipping material however did not affect the spread perpendicular or downhill.

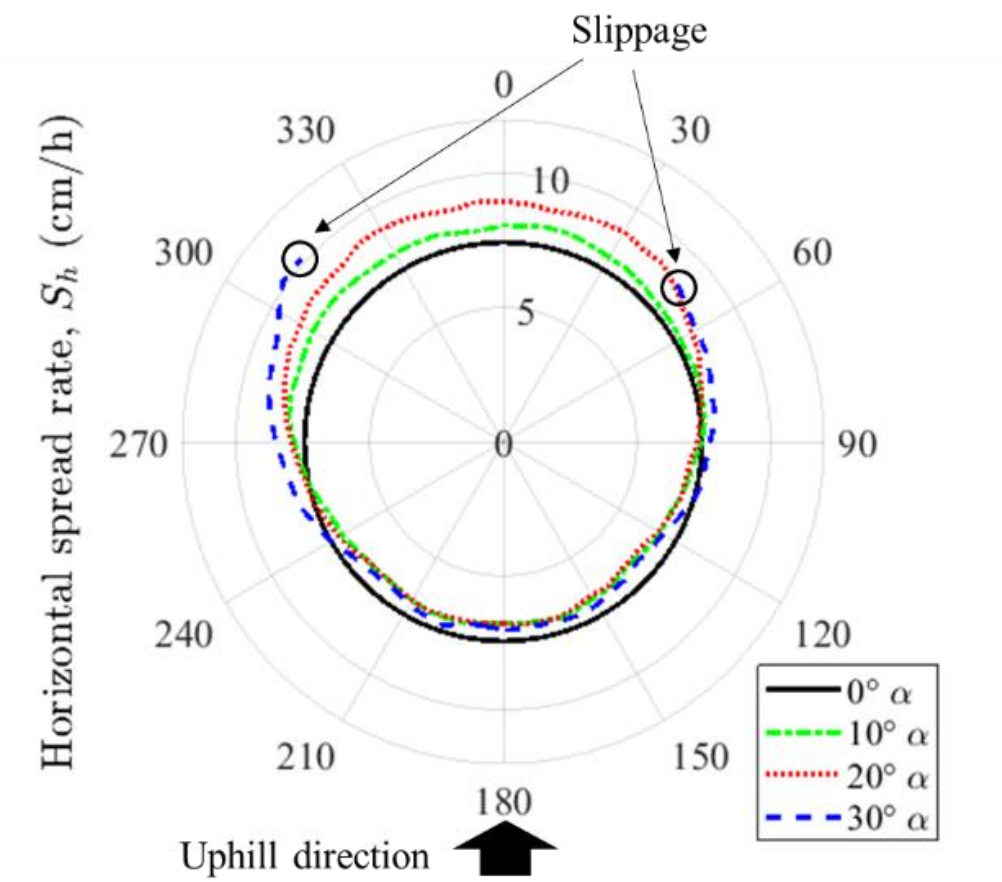

Figure 5 - Polar plot of the influence of slope on horizontal spread rate. Radial axis is spread rate (cm/h) and the angular axis is the direction $\theta_{s}$. Where 0, 90, and $180^{\circ}$ is uphill (forward), sidehill (perpendicular) and downhill (opposed), respectively. Spread rates affected by the slippage of peat were removed.

Overall, slope is found to have a similar influence on spread to wind due to the similarities in their fundamental mechanisms; hot air moves along the fuel surface uphill creating forward spread conditions, increasing the rate of heat transfer and cooling peat downhill [12]. This effect is more significant in flaming fires where heat transfer includes radiation, significantly increases spread uphill, but is typically unsteady and increases spread rate $\left(>10^{\circ}\right)[10]$. 
a)

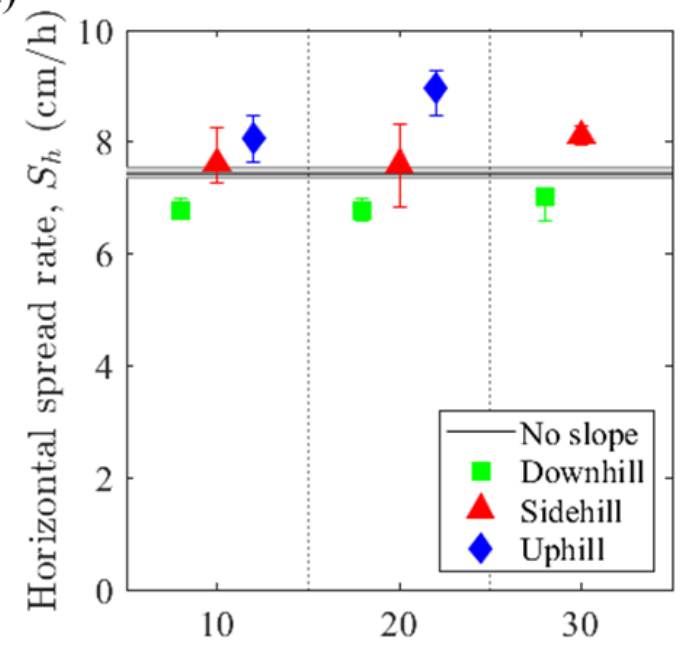

c)

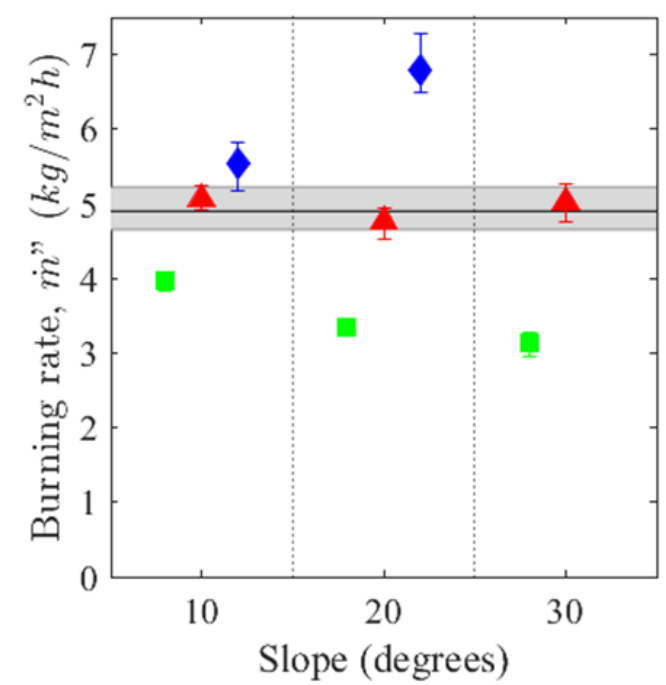

b)

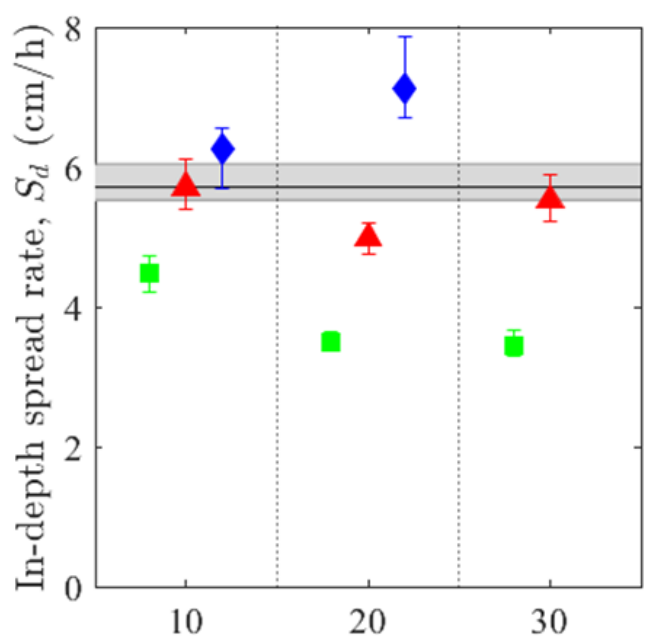

d)

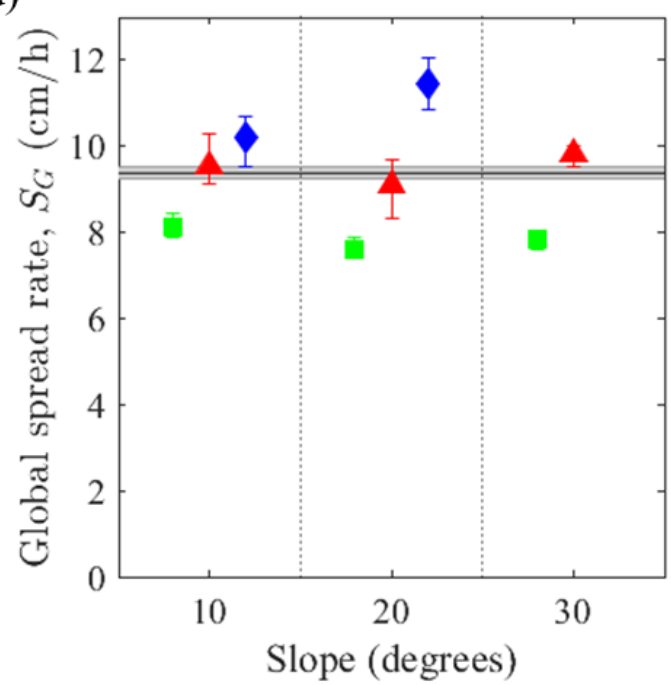

Figure 6 - The influence of slope on smouldering dynamics on a) horizontal spread, b) in-depth spread, c) burning rate, d) global spread rate, due to spread relative to the slope. Cases affected by the slippage of peat were removed. Values are averaged across 3 repeats while error bars provide the maximum and minimum spread of the repetitions. (Spread rate values are offset from their respective slopes and each slope conditions is separated by dotted lines.)

An increase with an uphill slope was also seen for in-depth spread (Figure 6 b), burning rate (Figure 6 c) and global spread rate (Figure $6 \mathrm{~d}$ ). However, the direction of the global spread was unaffected by slope (Figure S8). Downhill slopes decreased in-depth spread, burning rate, and global spread rate (Figure $6 \mathrm{~b}, \mathrm{c}$, and d). This is different from the results found for wind, where opposing wind had little effect on the spread dynamics. Notably, in-depth spread was more significantly affected by downhill spread then horizontal spread, decreasing by up to $40 \%$ compared to a $9 \%$ decrease in horizontal spread, relative to no-slope conditions. This decrease in in-depth spread may suggest a decreased availability of oxygen supply and may be an explanation as to the difference in behaviour opposed spread and downhill spread. Interestingly, the direction of the global spread rate tends towards horizontal (decreasing $\phi$; Figure S8) with increasing downhill slopes. Downhill spread experiences buoyancy induced winds that transports smoke away from the front, causing cold air to travel over the surface of the peat, increasing heat losses. Spread sideways to the hill has no considerable effect on the smouldering dynamics, behaving similarly to that of no slope (Figure 6). An overview of these finding is provided in Table S3. 
It was found that, regardless of the slope of the fuel bed, smouldering dynamics can be evaluated as a function of the spread angle $\beta$ from the horizontal plane. This can be calculated using Eq. 4 such that $\beta=\alpha$ when $\theta_{\mathrm{s}}=0^{\circ}$ (uphill, as illustrated in Figure 1), and $\beta=0^{\circ}$ when $\theta_{\mathrm{s}}=90^{\circ}$ (sidehill). Figure 7 shows how the horizontal spread rate, in-depth spread rate, burning rate and global spread rate of smouldering behaves similarly with respect to $\beta$, regardless of the overall slope $(\alpha)$. Figure S9 demonstrates this trend with $\phi$. This helps our understanding of how smouldering spreads on slopes. Flaming fires, which accelerate uphill, will not have a constant behaviour with $\beta$ making this analysis unfeasible [16]. However where spread travels downhill or on gentle gradients the spread angle $\beta$ may be useful and so deserves further research.
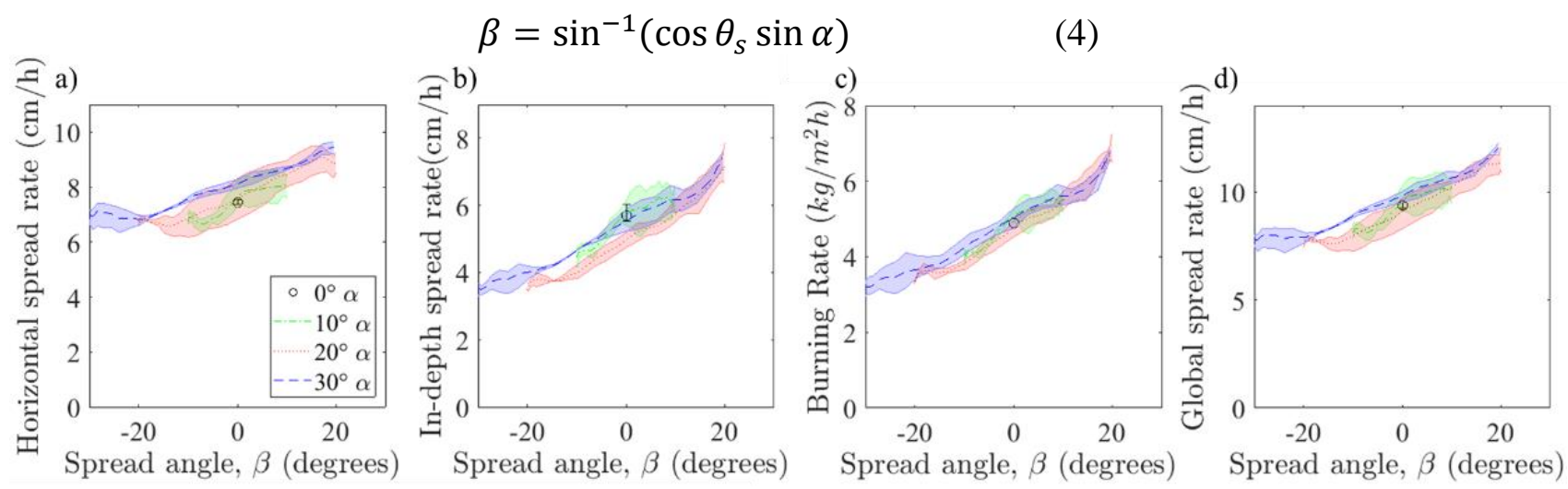

Figure 7 - Plotting averaged a) horizontal spread rate, b) in-depth spread rate, c) burning rate, and d) global spread rate as a function of $\beta$, which is the angle at which smouldering spreads relative to the horizontal plane. Spread affected by the slippage of peat were removed. The cloud error bars show the range in spread from the repetitions.

\section{Conclusion}

In this paper we present a systematic experimental study of both the influence of wind and slope on the smouldering dynamics of peat. Horizontal spread, in-depth spread, burning rate, and global spread responded to wind and slope in similar ways due to similar conditions of forward and opposed spread. Both horizontal and in-depth spread rates increased with forward wind up to 101 and $37 \%$ respectively between $0.84 \mathrm{~m} / \mathrm{s}$ wind speed and no-wind conditions. Opposed wind caused behaviour similar to that of no-wind conditions. The difference between forward and opposed spread was shown to increase with moisture. The effect of slope on smouldering dynamics could be analysed as a function of the spread angle, $\beta$, which helps analysis of smouldering spread on slopes. A $30^{\circ}$ increase in slope increased spread rates by up to $25 \%$, while sideways to the hill showed no difference when compared to no-slope. Downhill, on the other hand, decreased spread rates; an unexpected result as it is contrary to what is found in literature. Applying these findings to the field scale; forward wind and uphill slope, compared to in quiescent conditions and flat topographies, increase spread and burning rates, and are expected to result in greater fuel consumption and emissions. These findings give an insight into the fundamental interaction between smouldering fires and two important environmental conditions.

\section{Acknowledgments}

The authors thank the European Research Council (ERC) for funding through the Consolidator Grant HAZE (682587).

\section{References}

[1] G. Rein, Smouldering Fires and Natural Fuels, in: Fire Phenomena and the Earth System: An Interdisciplinary Guide to Fire Science, Wiley and Sons, 2013, 15-34, doi:

10.1002/9781118529539.ch2 
[2] I. Bertschi, R. J. Yokelson, D. E. Ward, R. E. Babbitt, R. A. Susott, J. G. Goode, W. M.Hao, Trace gas and particle emissions from fires in large diameter and belowground biomass fuels, Journal of Geophysical Research: Atmospheres 108 (2003), doi: 10.1029/2002JD002100 [3] M.R. Turetsky, B.Benscoter, S.Page, G.Rein, G.R. van der Werf, A. Watts, Global vulnerability of peatlands to fire and carbon loss, Nature Geoscience 8 (2014) 11-14, doi: 10.1038/ngeo2325 [4] S. Page, F. Siegert, J.O. Rieley, H.V. Boehm, A. Jaya, S.Limin, The amount of carbon released from peat and forest fires in Indonesia during 1997, Nature 420 (2002), 61-65 doi: 10.1038/nature01131

[5] W. Frandsen The influence of moisture and mineral soil on the combustion limits of smoldering forest duff, Canadian Journal of Forest Research 12 (1987) 1540-1544 doi: 10.1139/x87-236

[6] N. Prat-Guitart, G. Rein, R.M. Hadden, C.M. Belcher, J.M. Yearsley, Propagation probability and spread rates of self-sustained smouldering fires under controlled moisture content and bulk density conditions, International Journal of Wildland Fire 25 (2016) 456-465 doi: 10.1071/WF15103

[7] X. Huang, G. Rein, Downward Spread of Smoldering Peat Fire: the Role of Moisture, Density and Oxygen Supply, International Journal of Wildland Fire 26 (2017) 907-918, https://doi.org/10.1071/WF16198

[8] X. Huang, F. Restuccia, M. Gramola, G. Rein, Experimental study of the formation and collapse of an overhang in the lateral spread of smouldering peat fire, Combustion and Flame 168 (2016) 393402, https://doi.org/10.1016/j.combustflame.2016.01.017

[9] D. X. Viegas, Slope and wind effects on fire propagation, International Journal of Wildland Fire 13 (2004) 143-156, https://doi.org/10.1071/WF03046

[10] B.W. Butler, W.R. Anderson, E.A. Catchpole, Influence of slope on fire spread rate, USDA Forest Service Proceedings (2007) 75-82

[11] J. P. Valdivieso, J.D. Rivera, Effect of wind on smoldering combustion limits of moist pine needle beds 50 (2014) 1589-1605, doi: 10.1007/s10694-013-0357-2

[12] K. Palmer, Smouldering combustion in dusts and fibrous materials, Combustion and Flame 1

(1957) 129-154, doi: 10.1016/0010-2180(57)90041-X

[13] T.J.Ohlemiller, D.A.Lucca, An experimental comparison of forward and reverse smolder propagation in permeable fuel beds, Combustion and Flame 54 (1983) 131-147 Doi: 10.1016/00102180(83)90027-5

[14] J. Torero, A. C. Fernandez-Pello, M. Kitano, Opposed forced flow smoldering of polyurethane foam 91 (1993) 95-117, doi: 10.1080/00102209308907635

[15]S.L. Manzello, T.G. Cleary, J.R. Shields, J.C. Yang, On the ignition of fuel beds by firebrands, Fire and Materials 30 (2006) 77-87 doi: 10.1002/fam.901

[16] J.L. Dupuy Slope and fuel load effects on fire behaviour: laboratory experiments in pine needles

fuel beds, International Journal of WildlandFire 5 (1995) 153-164, doi: 10.1071/WF9950153

[17] E. G. Christensen N. Fernandez-Anez, G. Rein, Influence of Soil Conditions on the

Multidimensional Spread of Smouldering Combustion in Shallow Layers, Combustion and Flame 214 (2020) 361-370, doi: 10.1016/j.combustflame.2019.11.001

[18] T.J. Ohlemiller Forced smolder propagation and the transition to flaming in cellulosic insulation, Combustion and Flame 81 (1990) 354-365 doi: 10.1016/0010-2180(90)90031-L 
[Type here]

List of figures:

Figure 1 - Illustration of experimental set up for studying the influence of slope on smouldering dynamics, where when $\theta_{\mathrm{s}}$ is equal to 0 and $180^{\circ}$, smouldering spreads uphill or downhill, respectively.

Figure 2-A cross sectional illustrating the key features of smouldering dynamics (left), and a top view IR image showing how the features manifest (right). Figure is modified from [17]

Figure 3 - Polar plot of the influence of wind direction and MC on horizontal spread rate. Radial axis is spread rate $(\mathrm{cm} / \mathrm{h})$ while the angular axis is the direction $\theta_{\mathrm{w}}$. Where $\theta_{\mathrm{w}}=0,90$, and $180^{\circ}$ is forward perpendicular and opposed respectively.

Figure 4 - Influence of MC and wind direction on a) horizontal spread rate, b) in-depth spread rate, c) burning rate, and d) global spread rate. The results are offset from MC values and each moisture condition is separated by dotted lines. The error bars show the range of experimental results from three repetitions. The results for no wind conditions were taken from [17].

Figure 5 - Polar plot of the influence of slope on horizontal spread rate. Radial axis is spread rate $(\mathrm{cm} / \mathrm{h})$ and the angular axis is the direction $\theta_{\mathrm{s}}$. Where 0,90 , and $180^{\circ}$ is uphill (forward), sidehill (perpendicular) and downhill (opposed), respectively. Spread rates affected by the slippage of peat were removed.

Figure 6 - The influence of slope on smouldering dynamics on a) horizontal spread, b) in-depth spread, c) burning rate, d) global spread rate, due to spread relative to the slope. Cases affected by the slippage of peat were removed. Values are averaged across 3 repeats while error bars provide the maximum and minimum spread of the repetitions. (Spread rate values are offset from their respective slopes and each slope condition is separated by dotted lines.)

Figure 7 - Plotting averaged a) horizontal spread rate, b) in-depth spread rate, c) burning rate, and d) global spread rate as a function of $\beta$, which is the angle at which smouldering spreads relative to the horizontal plane. Spread affected by the slippage of peat were removed. The cloud error bars show the range in spread from the repetitions. 
[Type here]

\section{Supplementary material}

to

"Influence of Wind and Slope on Multidimensional Smouldering Peat Fires" Authors: Eirik G. Christensen ${ }^{1}$, Yuqi Hu${ }^{1}$, Dwi Purnomo ${ }^{1}$, Guillermo Rein ${ }^{1 *}$

${ }^{1}$ Imperial College London, London, Sw7 2AZ, UK

In the $38^{\text {th }}$ Proceeding of Combustion institute, 2020

This supplementary material contains additional information on experiments on the multidimensional smouldering spread peat, examining the effect of wind and slope and smouldering dynamics.

Experiments were conducted using a shallow open-top reactor, and spread rates were analysed using IR images. The first section supplies additional information on the samples and the experimental setup. Section 2 and 3 provides additional data on the effects of wind and slope respectively.

\section{Samples and Experimental Set-up}

Table S1 - Summary of average bulk and organic densities for all conditions. The results for the quiescent conditions are taken from [19] for comparison. Each condition was been performed 3 times.

\begin{tabular}{cccccccccccc}
\hline & \multicolumn{3}{c}{ Slope $(80 \% \mathrm{MC})$} & \multicolumn{3}{c}{ Wind } & \multicolumn{3}{c}{ Quiescent } \\
\hline & $10^{\circ}$ & $20^{\circ}$ & $30^{\circ}$ & $0 \% \%_{\mathrm{MC}}$ & $40 \%_{\mathrm{MC}}$ & $80 \%_{\mathrm{MC}}$ & $120 \%_{\mathrm{MC}}$ & $0 \% \%_{\mathrm{MC}}$ & $40 \%_{\mathrm{MC}}$ & $80 \%_{\mathrm{MC}}$ & $120 \% \mathrm{MC}$ \\
\hline$\rho_{\mathrm{b}}\left(\mathrm{kg} \mathrm{m}^{-3}\right)$ & 164 & 172 & 170 & 156 & 162 & 160 & 177 & 162 & 170 & 158 & 196 \\
$\rho_{\mathrm{o}}\left(\mathrm{kg} \mathrm{m}^{-3}\right)$ & 89 & 93 & 92 & 152 & 113 & 87 & 78 & 158 & 118 & 85 & 87 \\
\hline
\end{tabular}

\section{a)}

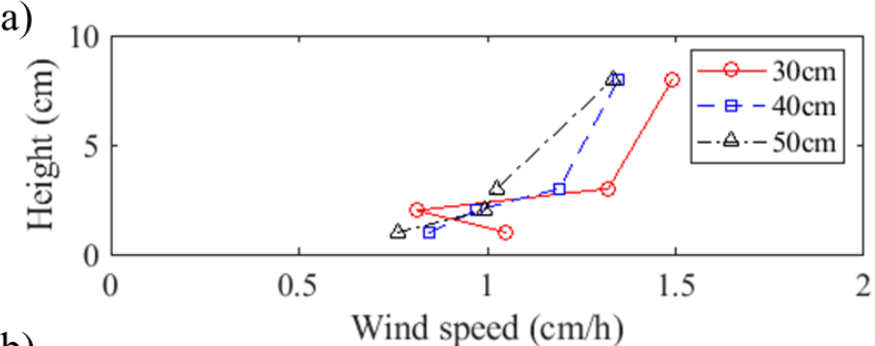

b)

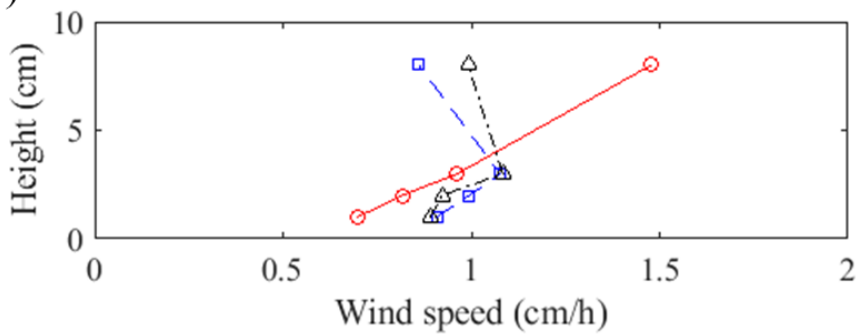

Figure S1 - Characterization of airflow profile. a) wind speed with height as various distances from the fan, down the centreline, b) wind speed with height as various distances from the fan, $7.5 \mathrm{~cm}$ from centreline. 


\section{[Type here]}
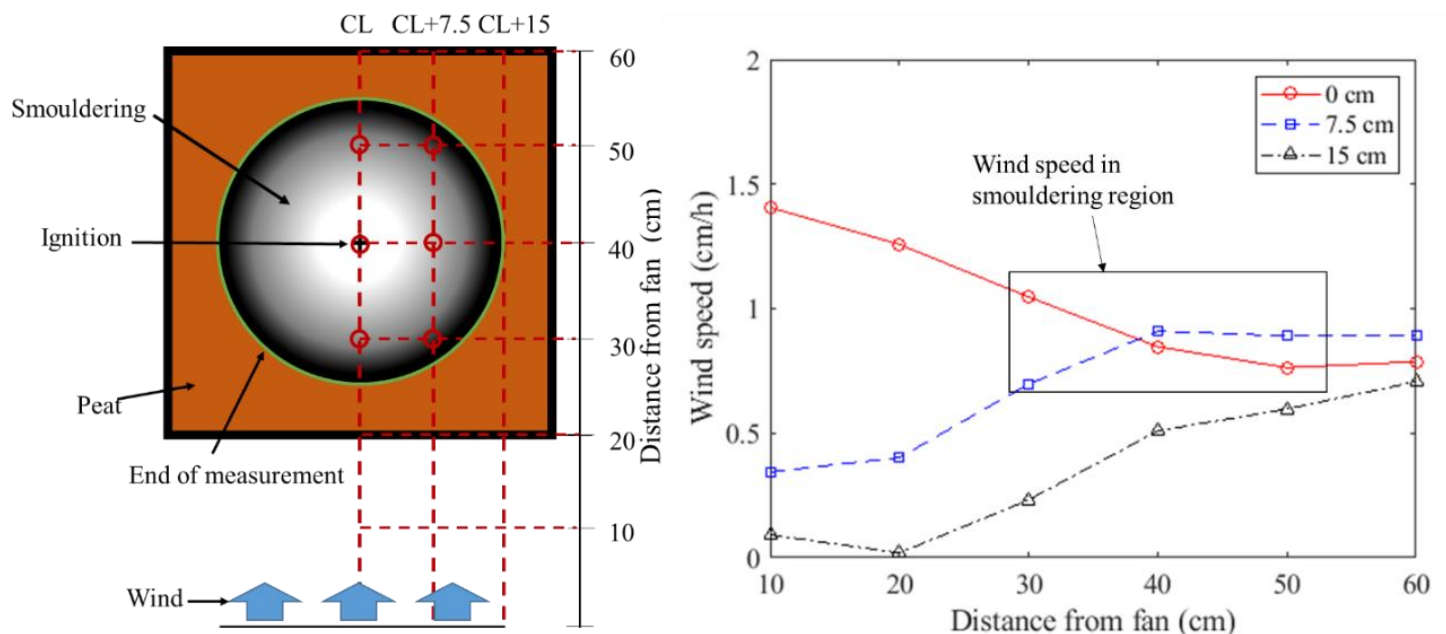

Figure S2 - Characterizing the wind speed effecting the smouldering spread. The illustration on the left is a top view of the reactor, where the intersection of the dotted lines indicate the location of wind speed measurements. The circled intersections are the locations that are averaged to yield the average wind speed affecting the spread. The study of smouldering spread was limited to within $14 \mathrm{~cm}$ of the ignition, indicated by the green circle. The figure on the right shows the wind speed $1 \mathrm{~cm}$ above the ground at various distances from the fan and at distanced from the centreline (CL) of the fan.

\section{a)}

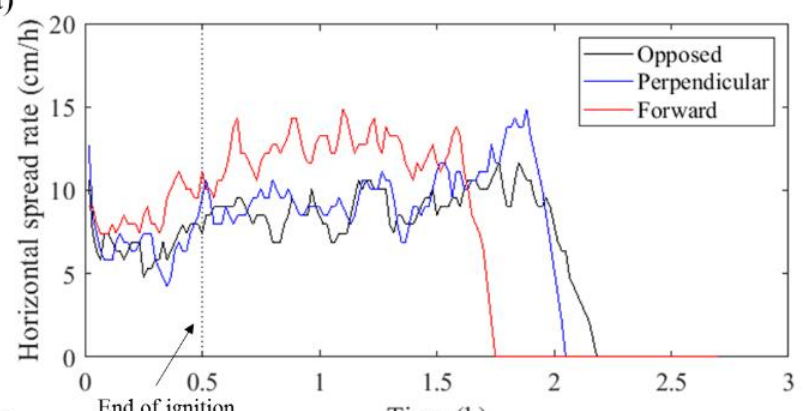

b)

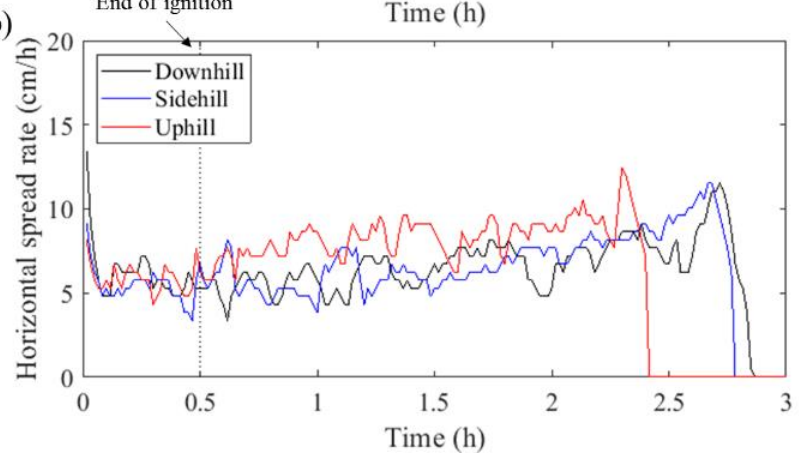

Figure S3 - Presenting examples of the consistent spread rate in all directions relative to a) wind and b) slope. 
[Type here]

The Effect of Wind on Smouldering Dynamics

a)

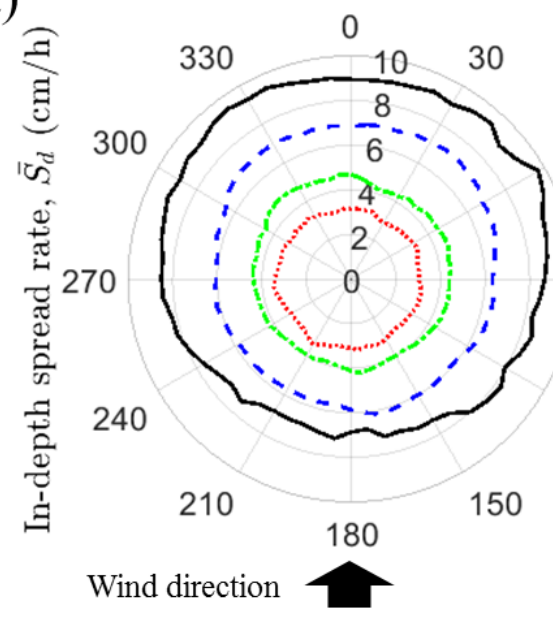

b)

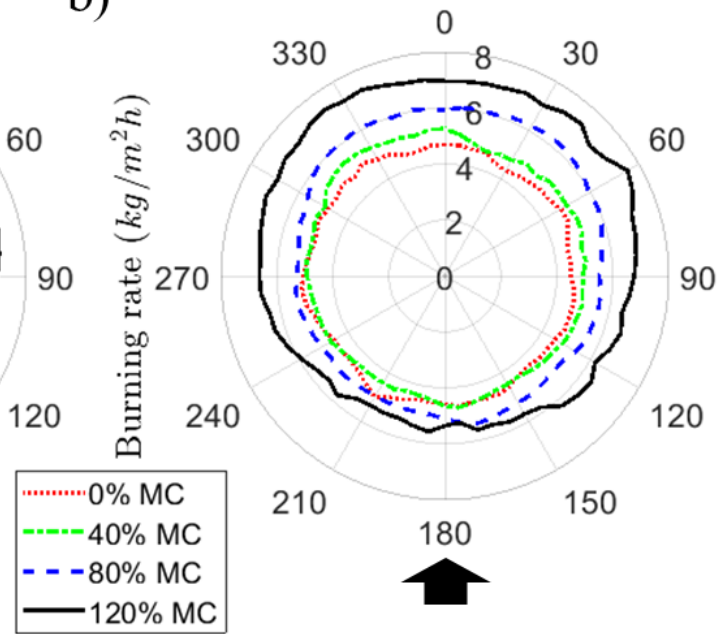

c)

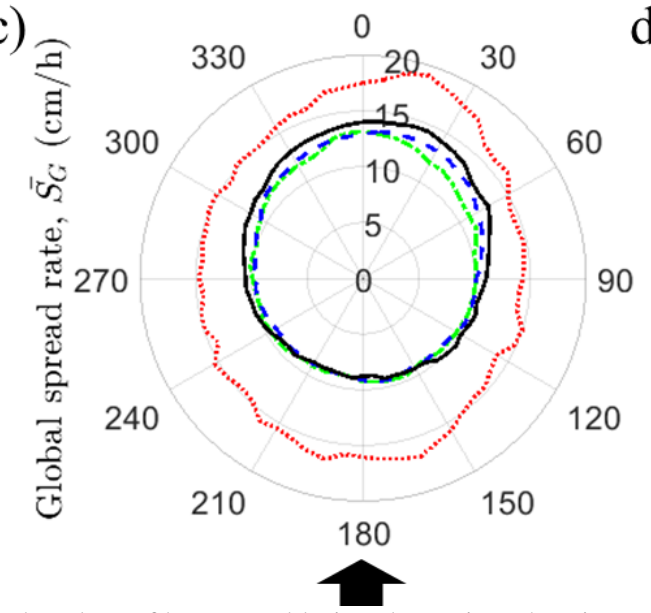

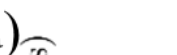

d)
90

Figure S4 - Polar plots of key smouldering dynamics, showing response to MC and all wind directions relative to spread. Angular axis is the direction of spread relative to the wind, where when $\theta_{\mathrm{w}}=0$ and 180 , spread is concurrent and opposite to wind respectively.

a)

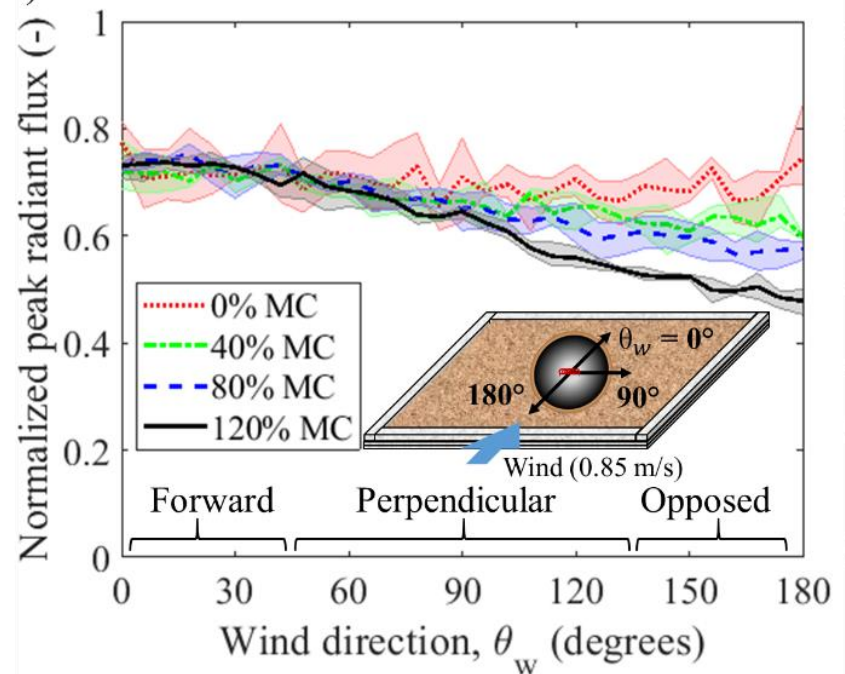

b)

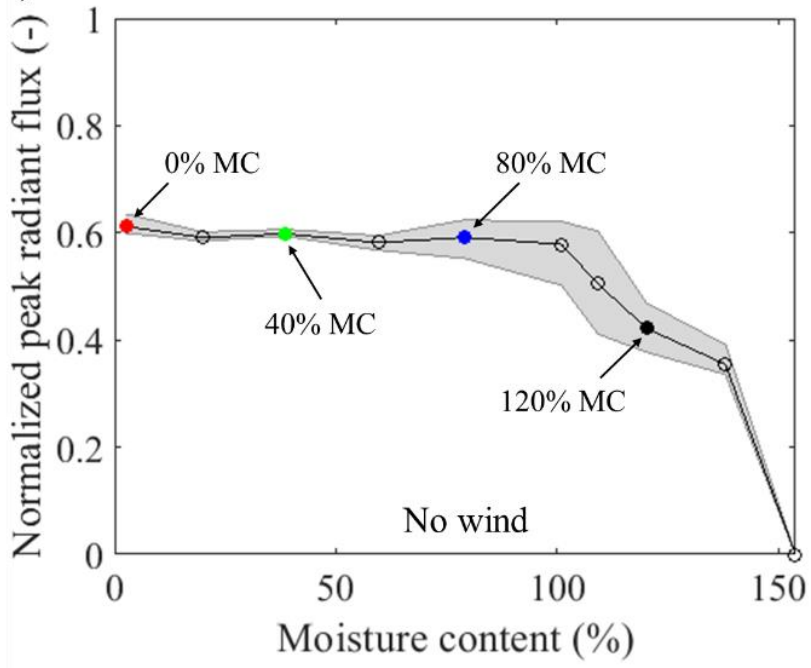

Figure S5 - a) Showing the variation of normalized heat flux with wind direction. Demonstrating the independence of heat flux from forward spread and decreasing heat flux from opposed spread with increasing MC. The results are average over 3 repeats for each MC conditio. b) demonstrates the influence of MC on peak radiant flux in quiescent conditions under no-wind conditions. The data for the right figure is of from [17]. All clouds show the range of results measured. 


\section{[Type here]}

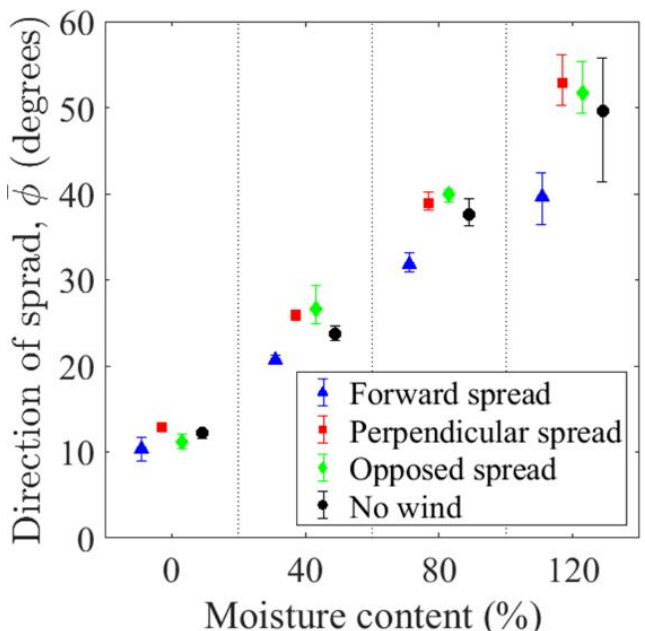

Figure S6 - Showing the change in direction of global spread with wind direction and comparing to no wind conditions taken from [17]. The results are offset from MC values and each moisture condition is separated by dotted lines. The error bars show the range of experimental results from three repetitions.

Table S2 - Effect of wind direction on smouldering dynamics. Percentage differences are noted relative to the no-wind condition for 0 , 40, 80 and $120 \% \mathrm{MC}$ respectively. Arrows upwards means an increase, arrow downward indicates a decrease, while $\sim$ means a negligible change.

\begin{tabular}{|c|c|c|c|c|c|}
\hline & Horizontal spread, $\mathrm{S}_{\mathrm{h}}$ & In-depth spread, $S_{d}$ & Burning rate, $\dot{m} "$ & Global spread, $\mathrm{S}_{\mathrm{G}}$ & Direction of spread, $\Phi$ \\
\hline Forward & $\uparrow(44,55,47,101 \%)$ & $\uparrow(22,33,19,37 \%)$ & $\uparrow(19,25,21,24 \%)$ & $\uparrow(43,52,38,65 \%)$ & $\downarrow(-15,-13,-15,-20 \%)$ \\
\hline Perpendicular & $\uparrow(18,14,3,21 \%)$ & $\uparrow(25,25,8,32 \%)$ & $\uparrow(22,17,10,20 \%$ & $\uparrow(19,15,5,27 \%)$ & $\sim(5,9,4,6 \%)$ \\
\hline Opposed & $\sim(32,4,-6,2 \%)$ & $\sim(20,18,3,5 \%)$ & $\sim(16,11,4,-4 \%)$ & $\sim(31,6,-2,3 \%)$ & $\sim(112,12,6,4 \%)$ \\
\hline
\end{tabular}




\section{[Type here]}

\section{The Effect of Slope on Smouldering Dynamics}

a)

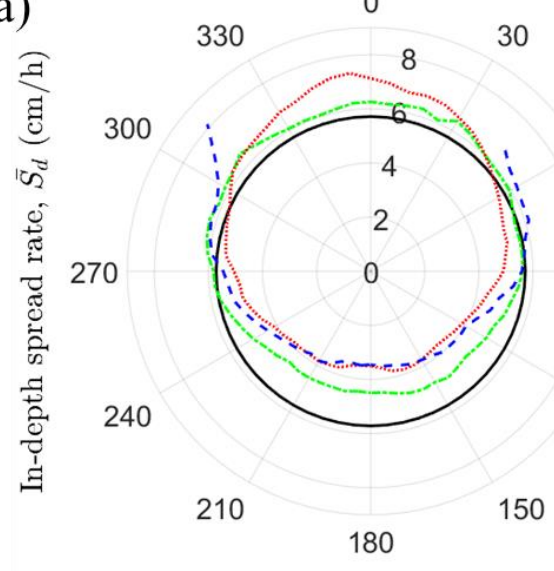

c)

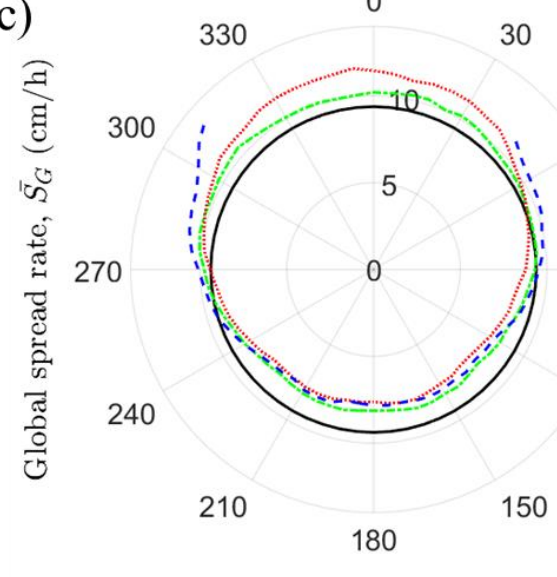

b)

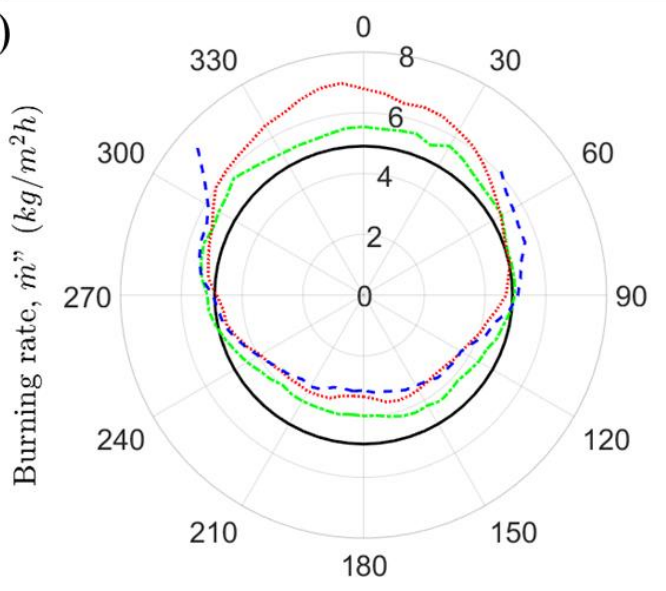

d)

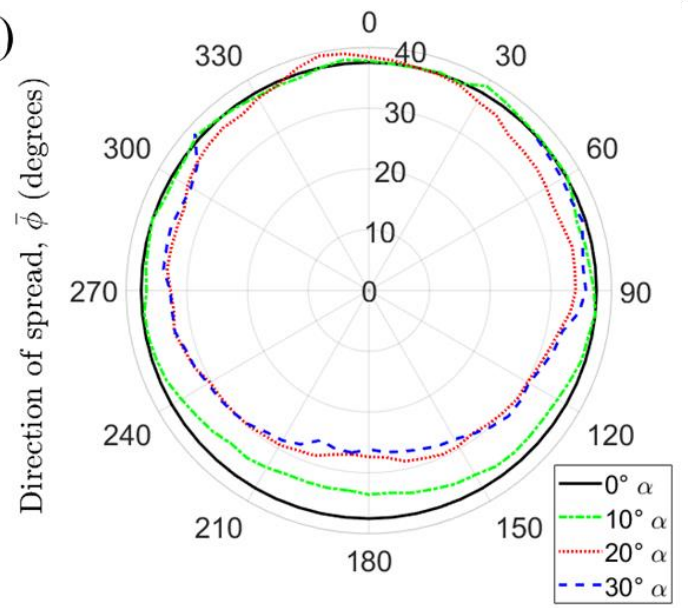

Figure S7 - Polar plots of a) in-depth spread rate b) burning rate c) global spread rate and d) direction of spread. The angular axis gives the direction $\theta$ of spread relative to the slope where when $\theta_{s}=0$ and $180^{\circ}$, spread is traveling up hill and downhill respectively.

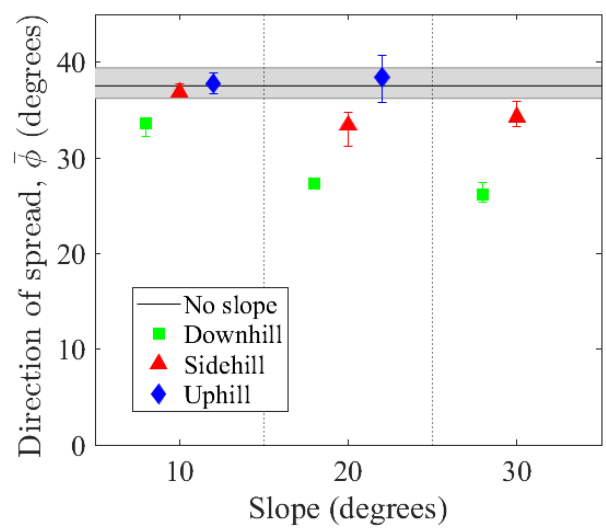

Figure S8 - showing the influence of spread direction relative to the slope on the global spread direction $\varphi$. Values are averaged across 3 repeats while error bars provide the maximum and minimum spread of the repetitions. (Spread rate values are offset from their respective slopes and each slope condition is separated by dotted lines.) 


\section{[Type here]}

Table S3 - Summarizing the effect of slope relative to spread on smouldering dynamics. Arrows indicates the relative change in behaviour to no-slope conditions. Percentages provide the average change for $0^{\circ}$ to 10,20 , and $30^{\circ}$ respectively. Where $\mathrm{x}$ is given, no value was found due to slippage of peat.

$$
\begin{array}{llll}
\text { Horizontal spread, } \mathrm{S}_{\mathrm{h}} & \text { In-depth spread, } \mathrm{S}_{\mathrm{d}} \quad \text { Burning rate, } \dot{\mathrm{m}}^{\prime \prime} \quad \text { Global spread, } \mathrm{S}_{\mathrm{G}} \quad \text { Direction of spread, } \Phi
\end{array}
$$

\begin{tabular}{cccccc}
\hline Uphill & $\uparrow(8,21, \mathrm{x} \%)$ & $\uparrow(10,25, \mathrm{x} \%)$ & $\uparrow(13,39, \mathrm{x} \%)$ & $\uparrow(9,22, \mathrm{x} \%)$ & $\sim(1,2, \mathrm{x} \%)$ \\
Sidehill & $\sim(3,2,9 \%)$ & $\sim(0,-13,3 \%)$ & $\sim(3,-3,2 \%)$ & $\sim(2,-3,5 \%)$ & $\sim(-2,-11,-9 \%)$ \\
& & & & $\downarrow$ \\
Downhill & $\downarrow(-9,-9,-6 \%)$ & $\downarrow(-21,-39,-40 \%)$ & $\downarrow(-19,-32,-36 \%)$ & $\downarrow(-13,-19,-17 \%)$ & $\downarrow(-11,-27,-30 \%)$ \\
\hline
\end{tabular}

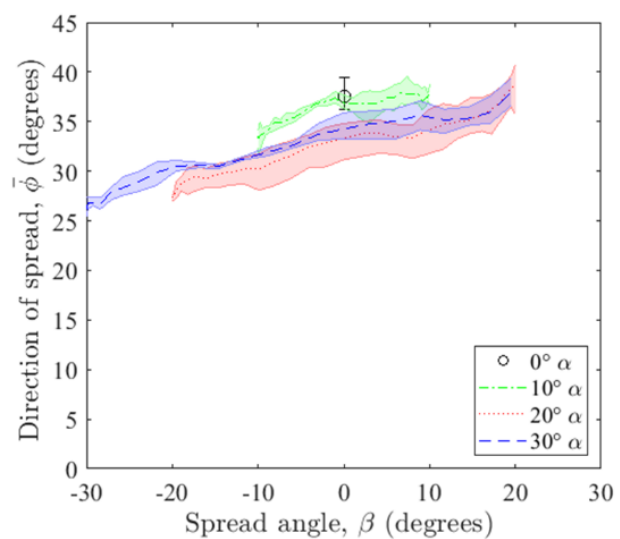

Figure S9 - Shows how the smouldering dynamics; a) in-depth spread b) burning rate c) global spread rate and d) direction of spread can be considered by the spread angle $\beta$. 